\title{
FINANCIAL INCLUSIONS, FINANCIAL STABILITY, AND INCOME INEQUALITY IN OIC COUNTRIES: A GMM AND QUANTILE REGRESSION APPLICATION
}

\author{
Fatima Muhammad Abdulkarim ${ }^{1}$ and Hamisu Sadi $\mathrm{Ali}^{2}$ \\ ${ }^{1}$ Federal University Dutse, Nigeria, fatimakarim@fud.edu.ng \\ ${ }^{2}$ Ahmadu Bello University, Nigeria, hamisusadi@gmail.com
}

\begin{abstract}
This paper examines the relationship among financial inclusion, financial stability, and income inequality in some selected Organization of Islamic Corporations (OIC) countries. Data were analyzed using dynamic panel estimation and quantile regression for 47 OIC countries during 2006 - 2016. The results of dynamic GMM reveal that financial inclusion has a positive and significant effect on both financial stability and income inequality. This implies that increased financial access helped narrow the gap between the rich and poor as well as provided financial stability in OIC countries. Therefore, policy makers should strive to design policies that will make financial services more available and affordable to the masses. Thus, it is safe to conclude that availability of both Islamic and conventional finances in OIC countries contributes positively to the development of the countries.
\end{abstract}

Keywords: Financial Inclusion, Financial Stability, Income Inequality, OIC Countries, GMM, Quantile Regression.

JEL Classification: D3; D63; D310; G0; G1.

\author{
Article history: \\ Received : October 29, 2018 \\ Revised : April 11, 2019 \\ Accepted : : May 26, 2019 \\ Available online : July 30, 2019 \\ https://doi.org/10.21098/jimf.v5i2.1069
}




\section{INTRODUCTION}

Recently, financial inclusion has become the buzzword in most economic discourse. It has become the main item on the agenda frequently discussed in both local and international platforms. Low-income countries are commonly found in developing than developed countries. Though more talked about in the former case $^{1}$ where financial exclusion has been a serious challenge confronting such economies, several policies were vigorously employed to ensure more people have access to finance. Sama (2008) defined financial inclusion as "a process that ensures the ease at which financial services are accessed, available and used by all members of an economy". According to World Bank (2013), around two billion people lack access to formal financial services globally, and out of this, over $50 \%$ of the population are found in developing countries as against the $10 \%$ figures in rich and developed countries. Therefore, it shows that access to finance is a serious problem confronting almost all developing economies.

Organization of Islamic Corporations (hereafter, OIC) countries' economies are mostly classified as developing economies and most of the country's population lacks the basic access to finance. The countries suffer a serious gap when compared with the rest of the world. Muslims voluntarily excludes themselves from financial system owing to some factors that ranges from religious and cultural ${ }^{2}$. However, with the availability of Islamic financial products offered in both Muslim and nonMuslim countries, more Muslims are attracted in to the financial system as the products offered conform to their religious beliefs and values.

Access to finance improves people's financial standing especially if finance is employed in productive economic sectors that generate more income to entrepreneurs, which directly improves productivity as well as economic development of a country. Empirical evidence shows that increased financial access raises the income levels of individuals especially in developed countries with higher bank accounts penetration and greater banks availability. In OIC countries, although there is evidence of more participation of people in the financial sector of the economy, little is known if such an aspect has succeeded in narrowing the income gap that exists between the rich and the poor. In a similar vein, as the main function of banks is to provide financial intermediation where funds from surplus units are channeled to the deficit units, the more customers in the banking system implies greater soundness in the system. In so doing, it further enhances the capital base of the banks with enough buffers to cushion any unexpected shocks that might potentially disrupt system wide stability.

Studies that analyze the relationship between financial inclusion on financial stability and income inequality are very limited. For instance, Kim et al., (2018) investigated financial inclusion and economic development in OIC countries. In OIC countries in particular, the concept of financial inclusion is still new and evolving. As financial inclusion increased tremendously in these countries, little is known whether this development has contributed to the general welfare of the

1. Financial inclusion in developing countries has received a great deal of attention by policy makers, economist as well as researchers.

2. Most people in Muslim countries refused to have an account with the formal banking sector for fear of taking interest that is prohibited in Islam. 
citizens through narrowing the gap that exists between the rich and the poor. Research by Kim et al., (2018) is the only study that employed OIC data to study the impact of financial inclusion on economic development. Their study, however, limits its focus to only economic growth without looking in to other aspects that financial inclusion could possibly have impact on such as financial stability and income inequality. Therefore, this study focused on the two additional areas (stability and income inequality) in order to bridge knowledge gap on this issue. Thus, the objective of this paper is to determine whether financial inclusion has contributed to narrowing or widening the gap between the haves and have not in OIC countries. It also explores how financial inclusion contributes to the general system stability of OIC countries.

By employing Ordinary Least Square (OLS) Regression, Static Fixed Effect (FE) and Random Effect (RE) Model, Generalized Method of Moments (GMM) and panel quantile regression, and using data from 47 OIC countries over the period 2006 - 2016, this paper makes the first attempt to empirically analyze the effect of financial inclusion on income inequality and financial stability owing to the dearth of research in OIC countries. Therefore, this paper intends to fill the gap in literature.

Using dynamic system GMM, the results of the study reveals that, with $\mathrm{GINI}^{3}$ as the dependent variable, financial inclusion significantly narrows the gap between the rich and poor in OIC countries. Similarly, using log of ZSCORE as the dependent variable, it is found that increased customer's access to banks as represented by ATM's increases financial stability in the selected countries. The results of quantile regressions also reveal evidence in support of positive effect of financial inclusion in narrowing the gap between the rich and the poor. It also demonstrates the stability of the economies as more and more people utilized the banking sector for productive purposes. More system stability is achieved there by boosting economic growth of the countries.

The reminder of the paper is organized as follows. Section 2 discusses the past literature on the link between financial inclusion, inequality and stability and also the theoretical aspect of finance and growth nexus. Data and methodology used are discussed in section three, while section four presents result and analysis, and chapter five conclusion and recommendation.

\section{LITERATURE REVIEW}

\subsection{Financial Inclusion, Poverty and Income Inequality}

World Bank defines poverty as "the deprivation in well-being, and comprises many dimensions. It includes low incomes and the inability to acquire the basic goods and services necessary for survival with dignity." Accordingly, increasing poverty is considered among the most pressing challenges facing the globe. Studies have attempted to link financial inclusion and poverty with inconclusive results. Studies by Bruhn, and Love (2014) reveal that facilitating better access to finance

3. GINI coefficient is an inequality measure which ranges from a value of 1.00 where the income of a particular country goes to one person only or a value of zero which signifies a well distribution of income among citizens. 
to the segment of the poor population has a positive effect on poverty alleviation. In a similar vein, Brune et al., (2011) documents increased financial access through commitment saving account improves the well-being of the poor by providing access to their saving for use of inputs for agricultural purposes.

A recent study by Perera and Lee (2013) examined Chinese Household survey data set to find whether the poor Chinese citizens used credit to finance costly consumption so as to copy the wealth consumption style of their neighbors. The study reveals evidence of proper use of credit by the poor households in economic activities that help them escape from the shackles of poverty.

Lack of access to finance has long been recognized as potential problem in widening the gap between the rich and poor. A study conducted in 2005 by Burgess and Pande reported that, rural poverty in India has been alleviated through the expansion of rural bank state-led expansion of bank branches in the country. They also reveal evidence to support the reduction of poverty rates in India is aided by opening of bank branches in rural unbanked locations in India. In a similar study by Allen et al., (2013) found that commercial banks' ability to provide financial services to underprivileged household in Kenya improves their financial access. Using data from MENA countries, Neaime and Gaysset, (2018) found that financially inclusion to have a significant reduction effect on income inequality. Kim (2016) also found that financial inclusion improves the relationship between financial income inequality and economic growth by changing the negative relationship in to a positive one.

The impact of financial inclusion on income inequality in Asia was investigated by Park and Mercado, (2015) who found financial inclusion to have significant reduction effect on poverty and income inequality in the selected countries. The authors further suggested measures to be employed in ensuring the low-income segment of the population are included in to their economic activities in order to gain from the economic prosperities of the countries. In another study by DablaNorris et al., (2015) found that, reduced transaction costs for the poor helps in increasing greater access to finance and narrowing income inequality. The authors, however, caution policy makers on policies aimed at reducing credit constraints will be of more benefit to the rich segment of the society against the poor segments and this can further exacerbate the inequality problems.

Policy makers in such countries have heavily debated the question on whether financial inclusion has any benefit to the poor segment of African economies. Most Africans are financially excluded from the financial system due to some factors that prevented them from opening bank account that ranges from religious and cultural. Tita and Aziakpono (2017) employed data from Sub-Saharan African countries and studies three characteristics of financial inclusion: electronic payments, formal savings and account use for business. The authors found a close connection between financial inclusion and income inequality in the countries. The authors suggest that the main reason for the widening gap in income between the rich and the poor is existence of massive financial exclusion as well as information asymmetry and moral hazard problems present in Africa. 


\subsection{Financial Inclusions and Financial Stability}

On the stability front, financial stability is essential to economic growth. This is because stable financial systems allow the efficient resources allocation and eliminate any market imperfection that exists in a financial system. Using microlevel data, a recent study by Ahamed and Mallick (2017) found that financial inclusion contributes to greater bank stability especially in countries with stronger institutional quality. In another study by Rashid et al., (2017), while studying on whether or not Islamic finance contributes to financial stability, the authors found that Islamic finance performed better than the conventional finance in stabilizing the financial system. Using Small Medium Enterprise (SME) data from 2004 to 2011, Morgan, (2014) found that increased lending to SMEs helps ameliorate financial stability by reducing the probability of default by financial institutions and also reducing non-performing loans (NPLs).

At macro-level, Al-Smadi, (2018) uses time series data from Jordan to examine the link between financial inclusion and financial stability from 2006 to 2017. His findings reveal positive and significant effect of financial inclusion on stability on the economy. Similarly, Dienillah et al., (2018) in their studies using higher income countries found significant positive effect of financial inclusion on the countries. The authors also found increased availability of financial services in lower and middle-income countries that significantly improved financial inclusion.

The literature establishes that research on financial inclusion is still growing and requires further investigations. Therefore, this study aims to fill the gap in literature on the link between financial inclusion, financial stability, and income inequality in selected OIC countries.

\subsection{Theoretical Framework}

\subsubsection{Finance and Growth Nexus}

Finance plays a vital role in the functioning of the economy. A well-functioning economy ensures that finance is made available to productive sectors of the economy, which will directly affect the overall economic development. By making funds available, economic agents will actively participate in commercial activities and the general well being of the agents will be improved there by narrowing the gap between the rich and the poor.

The last decade has witnessed debates on whether availability of finance contributes to the economic growth as well as narrows the gap between the rich and the poor. Theory provides differing expectations on the impact of finance on income inequality. A handful of theoretical models suggest positive effects of finance on income inequality. Galor and Moav (2004) indicate that by making finance available to businesses and households will lessen their credit constraints and help improve efficiency.

Researchers have attempted to empirically examine the relationship between finance and growth, finance and income inequality, and arrived at different conclusions, while some document a positive relationship between finance and inequality. In a study by Clarke et al. (2006) and Beck et al. (2007), the authors found positive effects of finance on income inequality. To illustrate, Beck et al. (2007) found financial helps narrow the gap between the rich and poor in the long 
and short run, and the effect is more pronounced for those in the lower income strata.

On the contrary, other researchers highlight the negative effect of finance on income inequality. Stiglitz (2012) in his book titled, "price of Inequality" suggests that financial sector expansion significantly contributed to widening the gap between the rich and poor. He analyzed data from United States and identified several channels through which relationship are affected such as, rent seeking, inefficient regulation, regulatory capture and supervision.

\section{DATA AND METHODOLOGY}

This study analyzes panel data of 47 OIC countries from 2006 to 2016 to study the effect of financial inclusion on stability and income inequality in the countries. Three indicators as proxy variables for financial inclusion are used namely: Automatic Teller Machines (ATMs) which measures how much individuals own bank accounts, bank branches per 100,000 (BANKBR) adults which measures the availability of banking services, and deposits accounts (DEPO) with commercial banks which represents the amount of people that have a formal bank account. The study also uses two dependent variables, which are ZSCORE and GINI to represent financial stability and income inequality respectively. Macroeconomic variables such as population growth rate (POP), Inflation (INF) as represented by consumer price index, trade as percentage of GDP (TRADE), age dependency ratio (AGER) and GDP per capita growth (GDPGR). The data is obtained from various sources based on availability. Financial inclusion data and ZSCORE for each country were retrieved from World Bank's Global Foundation for Democracy and Development (GFDD) and International Monetary Funds (IMFs) Financial Access Survey. GINI coefficient is retrieved from UNU-WIDER database. The data for controlled variables are obtained from World Development Indicators (WDI).

Table 1 shows the initial data analysis for data in both level and transformed form. The descriptive statistics are also presented in both level and differenced forms. In both level and differenced form, the mean of all the variables is positive with deposit rate and GDPGR having the highest (lowest) average values. BANKBR exhibited the highest volatility implying its riskiness over other variables. However, in difference form, the data did not exhibit extreme deviations as values are close to each other's. The results of panel unit root are presented in table 2 while that of co-integration test (Table 3 in Appendix) shows absence of spurious relationship among variables and all variables are co-integrated. 
Table 1.

Summary Statistics of Proxy Measures

\begin{tabular}{lccccc}
\hline Variable & Obs. & Mean & S.D & Min & Max \\
\hline Panel A: Level Data & & & & & \\
ZSCORE & 440 & 15.711 & 10.674 & 3.0316 & 63.87 \\
ATM & 440 & 20.375 & 22.399 & 0.0457 & 92.328 \\
BANKBR & 440 & 9.293 & 7.9765 & 0.36 & 42.331 \\
DEPO & 440 & 434 & 420.59 & 2.7825 & 1894 \\
AGER & 440 & 12.51 & 19.086 & 0.8739 & 101.83 \\
TRADE & 440 & 80.558 & 34.098 & 19.101 & 202.58 \\
GDPGR & 440 & 2.1981 & 8.1935 & -62.23 & 122.97 \\
POP & 440 & 2.6218 & 2.1105 & -0.767 & 16.332 \\
Panel B: Differenced Data & & & & & \\
Ln.ZSCORE & 440 & 2.5623 & 0.6207 & 1.1091 & 4.1569 \\
Ln.ATM & 440 & 2.1136 & 1.6175 & -3.085 & 4.5253 \\
Ln.BNKBR & 440 & 1.8372 & 0.9569 & -1.022 & 3.7455 \\
Ln.DEPO & 440 & 5.2877 & 1.5011 & 1.0233 & 7.5465 \\
Ln.AGER & 440 & 2.0072 & 0.8759 & -0.135 & 4.6233 \\
Ln.TRADE & 440 & 4.2984 & 0.4359 & 2.9497 & 5.3111 \\
Ln.GDPGR & 339 & 0.9982 & 0.9354 & -3.63 & 4.8119 \\
Ln.POP & 430 & 0.7819 & 0.6744 & -2.567 & 2.7931 \\
\hline
\end{tabular}

Table 2.

Panel Unit Root

\begin{tabular}{lcc}
\hline Variable & z-statistics & P-value \\
\hline ZSCORE & 9.57124 & 0.0000 \\
ATM & 12.4905 & 0.0000 \\
BANKBR & 12.5917 & 0.0000 \\
DEPO & 11.5726 & 0.0000 \\
AGER & 11.6975 & 0.0000 \\
POP & 12.5507 & 0.0000 \\
GDPGR & 12.8483 & 0.0000 \\
\hline
\end{tabular}

Notes: The dependent variable is represented by ZSCORE while ATM, BANKBR, DEPO denotes the independent variables and the controlled variables are POP, AGER, and GDPGR

\subsection{Methodology}

\subsection{Static Model Selection}

This study employed Fixed Effect (FE) and Random Effect (RE) estimators, which imposes equality of all scope coefficients (both short and long run), and equality in the error term across units or countries and allows only the intercepts to vary overtime. This model is therefore the most restrictive of all. It however creates a dummy variable and allows the intercept term to vary overtime and over crosssections. The same is true for random effect model except that it allows error variances and intercepts to differ across countries. The model selection criterion is based on the Hausman test statistics. If P-value is less than 5\%, this implies that the null hypothesis can be rejected and alternative (random effect model) is accepted. Therefore, the FE and RE model can be written as follows: 


$$
\begin{aligned}
& Y_{1, i \mathrm{t}}=\omega+\mathrm{FI}+\mathrm{ATM}+\mathrm{BANKBR}+\mathrm{DEPO}+\mathrm{CV}+\varepsilon \\
& Y_{2, \mathrm{it}}=\omega+\mathrm{FI}+\mathrm{ATM}+\mathrm{BANKBR}+\mathrm{DEPO}+\mathrm{CV}+\varepsilon
\end{aligned}
$$

Where $Y_{1, i t}$ and $Y_{2, i t}$ represent the two dependent variables (ZSCORE and GINI) of the models. ATM, BANKBR and DEPO are the three financial inclusion variables representing the independent variables. CV represents a vector of controlled variables namely: Inflation (INF), GDP per capita growth (GDPGR), trade openness (TRADE) and population growth (POP), while $\varepsilon$ the error term.

\subsection{Dynamic Panel GMM Estimation}

This study used generalized method of moment (GMM) using two-step systems developed by Blundell and Bond, (1998). This model addresses the weaknesses of fixed effect model. It specifically eliminates the presence of unobserved countryspecific effect by employing lags of independent variables to solve endogeneity problems present in panel data. It also uses a lagged dependent variable model to assess the dynamic nature of both dependent and independent variables in the model. The methodology also combines the regression in first differences with the regression in levels. To compute the system estimator, the variables in differences are instrumented with the lags of their own levels, while the variables in levels are instrumented with the lags of their own differences (Bond et al., 2009). The instruments validity can be tested using standard Sargan test of over-identifying restrictions. The non-rejection of null hypothesis implies that the instruments are valid and the models are correctly specified. Therefore, the following equation represents system GMM estimator:

$$
\begin{aligned}
& \text { Stability }=\omega \mathrm{y}_{\mathrm{it}-1}-\mathrm{y}_{\mathrm{i}, \mathrm{t}-2}+\beta \mathrm{X}_{\mathrm{it}}-\mathrm{X}_{\mathrm{i}, \mathrm{t}-2}+\left(\varepsilon_{\mathrm{it}}-\varepsilon_{\mathrm{i}, \mathrm{t}-2}\right) \\
& \text { Inequality }=\omega \mathrm{Y}_{\mathrm{i}, \mathrm{t}-1+} \beta \mathrm{X}_{\mathrm{i}, \mathrm{t}}+\theta \mathrm{Z}_{\mathrm{i}-1}+\left(\mu_{\mathrm{i}}+\mathrm{V}_{\mathrm{i}, \mathrm{t}}\right)
\end{aligned}
$$

Where:

Stability and inequality represents the two dependent variables in the study.

$\mathrm{Y}_{\mathrm{i}^{\prime} \mathrm{t}-1} \quad=$ Represents financial inclusion in year $\mathrm{t}-1$.

$\mathrm{X}_{\mathrm{i}} \quad=\mathrm{A}$ vector of financial inclusion explanatory variables.

$\mathrm{Z}_{\mathrm{t}} \quad=\mathrm{A}$ vector of lagged controlled variables.

$\mu_{\mathrm{i}} \quad=$ A representation of an observed country's time invariant effects.

\subsection{Panel Quantile Regression}

Quantile regression (hereafter QR) was introduced by Koenker and Bassett (1978) and has since been widely employed to analyze the dependence structure of financial variables and how it differs across different quantiles with regards to the distribution of the dependent variable. Specifically, $Q R$ allows the testing of the impact of conditional (independent) variables on different quintiles of the dependent variable. 
Let the dependent variable be $\mathrm{y}$, and it is assumed to be dependent on $\mathrm{x}$ in a linear fashion. Hence, the $\pi$ th conditional quantile function of $y$ is outlined below:

$$
\mathrm{Qy}(\tau / \mathrm{x})=\inf \{\alpha / \mathrm{Fy}(\alpha / \mathrm{x})>\tau\}=\sum \beta \mathrm{k}(\tau) \mathrm{Xk}=\mathrm{B}(\tau)
$$

Where Fy $(\alpha / x)$ represent the conditional distribution function of $y$ given $x$, and the QR coefficient $\beta(\tau)$ defines the dependence structure the exist between vector $\mathrm{x}$ and the $\tau$ th conditional quantile of $\mathrm{y}$. The overall dependence of $\mathrm{y}$ is determined by the values of $\beta(\tau)$ for $\tau \in[0,1]$.

The coefficients $\beta(\tau)$ for a given $\tau$ are estimated by minimizing the weighted absolute deviations between $\mathrm{y}$ and $\mathrm{x}$ :

$$
\beta(h a t)(\tau)=\arg \min \sum(\tau-1\{y t<x t \beta(\tau\}, y t-x t \beta(\tau)
$$

Where 1 fyt $<\mathrm{xt} \beta(\tau)$ is the actual indicator function.(Koenker, and D'Orey, (1987) suggested a liner-programming algorithm in other to solve this problem. In addition, the standard error can be obtained using pair bootstrapping method.

\section{RESULTS AND ANALYSIS}

\subsection{Ordinary Least Square Regression (OLS)}

The analysis begins with a discussion of Ordinary Least Square (OLS) Regressions. Such a technique is heavily criticized in literature due to the inherent biased that may render results to be misleading and arrive at incorrect conclusions. However, the OLS results are later compared with a more dynamic technique (GMM) in the subsequent section. Table 4 and Table 5 (column (1-2)) reports the OLS results. Based on Table 4 (column (1-2)) it is found that ATM has a negative and significant effect on income inequality at $1 \%$ significant level. This shows that when the number of ATM increases, the gap between the rich and the poor in OIC countries is narrowed. It is expected as more people own formal bank accounts, they utilize it to engage in productive activities that will improve their lives thereby making them more economically well off. The variables BANKBR and DEPO have a positive and significant relation for the former and insignificant relationship for the latter. This implies that more bank branches widen the gap between the rich and the poor. This is somehow perplexing as more branches should make financial services more visible and accessible to people.

In a similar vein, Table 5 (column (1-2)) shows the OLS results using ZSCORE as the dependent variable. The results are similar to that obtained using GINI as the dependent variable with the exception of deposit (DEPO), which entered in to the model with a negative sign. This shows that as customer's deposits increase in banks, the stability of the banking system is threatened. This might be due to the fact that as funds flows from surplus units to the deficit unit, the latter might invest the resources in speculative economic activities, which might negatively affect the stability of the economies. 


\subsection{The Static Model}

Before delving in to result discussion, let us discuss the preliminary tests that suggest the appropriate models to be employed are examined and then the results are presented in Table 4 and Table 5 (column (3-4)). The study first employed the Hausman test and obtained a p-value of 0.012. A Hausman test value that is greater than $5 \%$ suggests that the fixed effect model has been acceptable. The p-value found in this study is greater than $5 \%$ for both the dependent variable GINI. This indicates that the null hypothesis of random effect model is rejected and hence, the alternative (fixed effect) model is better and is therefore employed in the study. As for the dependent variable ZSCORE, the Hausman test value suggests the use of Random Effect model that is presented in Table 5 (column 3-4)). This confirms that the model is well specified.

Table 4 (column (3-4)) reports the findings of FE model using GINI as the dependent variables. The result depicts that, ATM has a negative and significant effect on the relationship between financial inclusion and inequality in all models. This negative relationship implies that as more people have access to financial services, income inequality declines, which means that more people from lowerincome strata of the population are able to access financial services thereby narrowing the inequality gap. The findings of BANKBR reveals a positive and statistically significant at $1 \%$ significant level. This implies that, when the number of bank branches increase by $1 \%$, income inequality increases by $13 \%$. This suggests that increased bank presence in OIC countries did not assist in narrowing inequality gap. In addition, it is found DEPO has a negative and insignificant signs in all models. This shows that the variable is not effective in influencing the relationship between inequality and financial inclusion.

Using log of ZSCORE as the dependent variable, Table 5 (column 3-4)) also shows the empirical findings using RE model. The results suggest that ATM and BANKBR have a positive relationship with financial stability. The result is statistically significant at $5 \%$ and $10 \%$ respectively. The findings are in line with that of Neaime and Gaysset, (2018) who found the factors to be influential in promoting financial stability in MENA countries. The opposite findings were reported by Ahamed and Mallick, (2017). 
Table 4.

Panel Results - OLS, Fixed Effect and GMM Estimation

\begin{tabular}{|c|c|c|c|c|c|c|c|}
\hline $\begin{array}{l}\text { Dependent Variable } \\
\text { GINI }\end{array}$ & OLS [1] & OLS [2] & FE [1] & FE [2] & $\begin{array}{c}\text { GMM } \\
\text { [1] }\end{array}$ & $\begin{array}{c}\text { GMM } \\
{[2]}\end{array}$ & $\begin{array}{c}\text { GMM } \\
{[3]}\end{array}$ \\
\hline \multirow[t]{2}{*}{ Ln.GINI } & - & - & - & - & $0.673^{* * *}$ & $0.752^{* * *}$ & $0.707^{* * *}$ \\
\hline & - & - & - & - & {$[8.06]$} & {$[9.60]$} & {$[8.00]$} \\
\hline \multirow[t]{2}{*}{ Ln.POP } & -0.011 & 0.01 & -0.094 & -0.095 & $0.054^{* * *}$ & $0.047^{* * *}$ & $0.080^{* *}$ \\
\hline & {$[0.018]$} & 0.02 & {$[-0.53]$} & {$[-0.54]$} & {$[3.76]$} & {$[3.86]$} & {$[2.30]$} \\
\hline \multirow[t]{2}{*}{ INF } & -0.004 & -0.003 & 0.002 & 0.002 & $-0.002^{* *}$ & $-0.002^{* * *}$ & -0.001 \\
\hline & [0.003] & {$[0.002]$} & {$[1.40]$} & {$[1.54]$} & {$[-2.18]$} & {$[-3.00]$} & {$[-1.30]$} \\
\hline \multirow[t]{2}{*}{ AGER } & $0.37^{* * *}$ & $0.34^{* * *}$ & -0.002 & -0.002 & $0.001^{* *}$ & $0.001^{* * *}$ & $0.002^{* * *}$ \\
\hline & {$[0.075]$} & {$[0.01]$} & {$[-0.58]$} & {$[-0.61]$} & {$[2.39]$} & {$[2.76]$} & {$[2.92]$} \\
\hline \multirow[t]{2}{*}{ TRADE } & -0.028 & -0.033 & $-0.003^{* * *}$ & $-0.003^{* * *}$ & $0.000^{*}$ & $0.000^{* *}$ & 0 \\
\hline & {$[0.056]$} & {$[0.05]$} & {$[-3.95]$} & {$[-4.06]$} & {$[1.74]$} & {$[2.44]$} & {$[0.30]$} \\
\hline \multirow[t]{2}{*}{ GDPGR } & 0.015 & 0.01 & 0.000 & - & $0.001^{* * * *}$ & $0.002^{* * *}$ & 0.001 \\
\hline & {$[0.023]$} & 0 & {$[-0.27]$} & - & {$[2.79]$} & {$[5.28]$} & [1.46] \\
\hline \multirow[t]{2}{*}{ ATM } & $-0.01^{* * *}$ & $-0.01^{* * *}$ & $-0.003^{* * *}$ & $-0.003^{* * *}$ & $-0.000^{*}$ & - & - \\
\hline & {$[0.016]$} & {$[0.014]$} & {$[-3.73]$} & {$[-3.75]$} & {$[-1.82]$} & - & - \\
\hline \multirow[t]{2}{*}{ BANKBR } & $0.10^{* * *}$ & $0.10^{* * *}$ & $0.013^{* * *}$ & $0.013^{* * *}$ & - & -0.000 & - \\
\hline & [0.027] & {$[0.02]$} & {$[4.13]$} & {$[4.20]$} & - & {$[-0.01]$} & - \\
\hline \multirow[t]{2}{*}{ DEPO } & 0.018 & 0.02 & -0.018 & -0.017 & - & - & $-0.059^{* * *}$ \\
\hline & {$[0.0310]$} & {$[0.03]$} & {$[-0.44]$} & {$[-0.43]$} & - & - & {$[-3.34]$} \\
\hline Cons. & 2.28 & 2.42 & 5.505 & $5.531^{*}$ & 0.16 & -0.002 & -0.441 \\
\hline \multirow[t]{2}{*}{ R2 } & 0.38 & 0.36 & - & - & - & - & - \\
\hline & {$[0.72]$} & {$[0.66]$} & [1.67] & [1.69] & {$[0.40]$} & {$[-0.01]$} & {$[-0.91]$} \\
\hline $\mathrm{N}$ & 76 & 83 & 83 & 83 & 65 & 65 & 65 \\
\hline No. of groups & - & - & 18 & 18 & 65 & 65 & 65 \\
\hline Sargan & - & - & - & - & 6.53 & 6.34 & 6.25 \\
\hline Sargan Prob. & - & - & - & - & [0.988] & {$[0.964]$} & [0.946] \\
\hline $\operatorname{AR}(1)$ & - & - & - & - & -1.178 & -1.166 & -1.164 \\
\hline AR[1] Prob. & - & - & - & - & [0.239] & {$[0.225]$} & {$[0.216]$} \\
\hline AR [2] & - & - & - & - & -0.047 & -0.042 & -0.364 \\
\hline AR [2] Prob. & - & - & - & - & {$[0.0964]$} & [0.0954] & [0.094] \\
\hline
\end{tabular}

Note: The dependent variable is Ln.GINI. The values in bracket represent $t$ statistics. ${ }^{*}, * * * * *$ indicates statistical significance at the 10,5 and $1 \%$ levels respectively.

Regarding the macroeconomic factors that might affect the relationship among the variables in both Table 4 and Table 5 (column (3-4)), only TRADE is found to be significant at $1 \%$ significant level. Here, the result shows a negative relationship between trade openness and income inequality in OIC countries. This suggests that, as the volume of trade in OIC countries increases, more opportunities are available to businesses that directly help in boosting their capital base resulting in increased profitability. 


\subsection{Dynamic Panel Model Estimations}

So far, we run OLS, Fixed Effect, and Random Effect model estimations without exploiting panel dimensions of the data. Analyzing the panel structure of the data will allow us to remove any unobserved time-invariant country-specific heterogeneity. Therefore, this section employed the two-step system generalized method of moment (GMM) estimator proposed by Blundell and Bond (1998). Table 4 (column 5-7)) shows that all the coefficients of ATM, BANKBR and DEPO entered all the regression models with a negative signs signifying that financial inclusion reduces the gap between the rich and the poor in OIC countries. This suggests that, increased bank penetration in OIC countries makes financial services available to the lower strata of the population and hence, eases inequality problem. The results echoed the findings of Cyn-Young and Mercado, (2015) and Honahan, (2007) who documents a negative relationship between income inequality and financial inclusion for their full sample series.

Using log of ZSCORE as the dependent variable, Table 5 (column (5-7)) shows that ATM has a positive and statistically significant effect on financial stability at $5 \%$ level. This implies that, as more people own banks account, the banks become more competitive and efficient thereby boosting system stability. Similar results were reported by Neaime and Gaysset (2018) who argued that as more ATM increases, financial stability increases. The coefficient of BANKBR also has a positive and insignificant effect on financial stability. This suggests that, more bank branches in OIC countries contribute to improvement in the countries financial stability. This is expected as more OIC countries liberalizes their financial systems, more foreign capital flows in to the financial system of the countries resulting in increased financial development and stability across most countries especially for countries like UAE, Malaysia, Indonesia, Saudi Arabia, Tunisia and Morocco. The Variable deposit (DEPO) has a negative and significant effect on financial stability at $1 \%$ significant level.

By the same token, on the controlled variables in Table 4 (column 5-7)), population, age dependency ratio, trade openness and GDP per capita growth are found to affect income inequality. For example, in the last decade, the population of the Muslim countries have increased significantly especially in countries like Indonesia and Nigeria. This is why it has been projected that Muslim customers will form a large portion of the global purchasing power population. In contrast, Table 5 (column 5-7) reports negative relationship between population growth and financial stability. This implies that, the increase in population growth in OIC countries significantly affects its financial stability.

Turning on to Sargan test of over- identifying restrictions, the high p-values suggest that the null hypothesis cannot be rejected and the over-identifying restrictions are valid. Therefore, the Sargan tests result is in line with the GMM theory and as such poses no threat to the validity of the instrumental variables. Also, AR (2) test for second order serial correlation and the results reveals that the data were asymptotically distributed where a p-value of more than 0.05 shows absence of serial correlation using the second order by taking the first difference of the error terms. 
Table 5.

Panel Results- OLS, Random Effect and GMM Estimations

\begin{tabular}{|c|c|c|c|c|c|c|c|}
\hline $\begin{array}{l}\text { Dependent Variable } \\
\text { ZSOCRE }\end{array}$ & OLS [1] & OLS [2] & RE [1] & RE [2] & $\begin{array}{c}\text { GMM } \\
\text { [1] }\end{array}$ & $\begin{array}{c}\text { GMM } \\
\text { [2] }\end{array}$ & $\begin{array}{c}\text { GMM } \\
{[3]}\end{array}$ \\
\hline \multirow[t]{2}{*}{ Ln.ZSCORE } & - & - & - & - & $0.673^{* * *}$ & $0.752^{* * *}$ & $0.707^{* * *}$ \\
\hline & - & - & - & - & {$[8.06]$} & {$[9.60]$} & {$[8.00]$} \\
\hline \multirow[t]{2}{*}{ Ln.POP } & 0.022 & $0.13^{* * *}$ & -0.094 & -0.095 & $0.054^{* * *}$ & $0.047^{* * *}$ & $0.080^{* *}$ \\
\hline & {$[0.059]$} & {$[0.05]$} & {$[-0.53]$} & {$[-0.54]$} & {$[3.76]$} & [3.86] & {$[2.30]$} \\
\hline \multirow[t]{2}{*}{ INF } & - & - & 0.002 & 0.002 & $-0.002^{* *}$ & $-0.002^{* * *}$ & -0.001 \\
\hline & - & - & {$[1.40]$} & {$[1.54]$} & {$[-2.18]$} & {$[-3.00]$} & {$[-1.30]$} \\
\hline \multirow[t]{2}{*}{ AGER } & -0.112 & -0.064 & -0.002 & -0.002 & $0.001^{* *}$ & $0.001^{* * *}$ & $0.002^{* * *}$ \\
\hline & {$[0.051]$} & [0.043] & {$[-0.58]$} & {$[-0.61]$} & [2.39] & {$[2.76]$} & [2.92] \\
\hline \multirow[t]{2}{*}{ TRADE } & 0.297 & $0.30^{* * *}$ & $-0.003^{* * *}$ & $-0.003^{* * *}$ & $0.000^{*}$ & $0.000^{* *}$ & 0.000 \\
\hline & {$[0.08]$} & {$[0.071]$} & {$[-3.95]$} & {$[-4.06]$} & {$[1.74]$} & {$[2.44]$} & {$[0.30]$} \\
\hline \multirow[t]{2}{*}{ GDPGR } & -0.099 & - & -0.000 & - & $0.001^{* * *}$ & $0.002^{* * *}$ & 0.001 \\
\hline & {$[0.035]$} & - & {$[-0.27]$} & - & {$[2.79]$} & {$[5.28]$} & [1.46] \\
\hline \multirow[t]{2}{*}{ ATM } & -0.063 & -0.086 & $0.003^{*}$ & $0.003^{*}$ & $0.000^{*}$ & - & - \\
\hline & {$[0.03]$} & [0.027] & {$[3.73]$} & [3.75] & [1.82] & - & - \\
\hline \multirow[t]{2}{*}{ BANKBR } & 0.2363 & $0.25^{* * *}$ & $0.013^{* *}$ & $0.013^{* *}$ & - & 0.000 & - \\
\hline & {$[0.058]$} & {$[0.052]$} & {$[4.13]$} & {$[4.20]$} & - & {$[0.01]$} & - \\
\hline \multirow[t]{2}{*}{ DEPO } & -0.044 & -0.019 & -0.018 & -0.017 & - & - & $-0.059^{* * *}$ \\
\hline & {$[0.035]$} & {$[0.032]$} & {$[-0.44]$} & {$[-0.43]$} & - & - & {$[-3.34]$} \\
\hline \multirow[t]{2}{*}{ Cons } & 1.485 & 1.105 & 5.505 & $5.531^{*}$ & 0.160 & -0.002 & -0.441 \\
\hline & {$[0.38]^{*}$} & {$[0.338]^{*}$} & [1.67] & [1.69] & {$[0.40]$} & {$[-0.01]$} & {$[-0.91]$} \\
\hline R2 & 0.11 & 0.13 & & & & & \\
\hline $\mathrm{N}$ & 329 & 430 & 430 & 430 & 385 & 385 & 385 \\
\hline No. of groups & - & - & 46 & 46 & 46 & 46 & 46 \\
\hline Sargan & - & - & - & - & 39.09 & 39.06 & 39.01 \\
\hline Sargan - Prob & - & - & - & - & [0.922] & [0.910] & [0.905] \\
\hline $\mathrm{AR}(1)$ & - & - & - & - & -3.139 & -3.12 & -3.015 \\
\hline AR(1) -Prob & - & - & - & - & {$[0.017]$} & {$[0.014]$} & {$[0.011]$} \\
\hline $\operatorname{AR}(2)$ & - & - & - & - & 0.0495 & 0.0446 & 0.043 \\
\hline AR(2) - Prob & - & - & - & - & {$[0.96]$} & {$[0.93]$} & {$[0.9]$} \\
\hline
\end{tabular}

Note: The dependent variable is Ln.ZSCORE. The values in bracket represent $t$ statistics. ${ }^{*},{ }^{* *},{ }^{* * *}$ indicate statistical significance at the 10,5 and $1 \%$ levels respectively.

\subsection{Robustness Test: Panel Quantile Regression Estimates}

Table 6 reports the QR estimates of the results of the effect of financial inclusion on stability and income inequality in OIC countries. The OLS estimates are presented in column 1 of the Table 6 while the remaining columns present the QR estimates. The result of OLS shows a positive and significant impact of BANKBR on financial stability. However, the result of QR shows that the relationship between BANKBR and financial stability is not consistent at different quantiles. At $1 \%$ significant level, the QR coefficient of ATM are statistically significant at quantiles 0.25 and 0.50. They became negative and insignificant for 0.75 and 0.90 . According to OLS, deposits have no impact on Z-SCORE as evidenced by the insignificance of the coefficient. However, positive and significant coefficients are obtained in QR 0.75 
and 0.90 respectively. From the perspective of population (POP), age (AGER), GDP (GDPGR) and trade (TRADE), the result differs between OLS and QR. For example, in OLS in Table 6, it reveals a negative and insignificant result for AGER and GDPGR and positive and significant for POP and TRADE, while they have no impact in quantile regression at different quantiles.

Table 6.

Panel Quantile Regression Estimates

\begin{tabular}{lccccc}
\hline Variables & OLS_res & Q25_res & Q50_res & Q75_res & Q90_res \\
\hline ATM & -0.076731 & $-0.01^{* *}$ & $0.00934^{*}$ & -0.1812 & -0.2136 \\
BANKBR & $0.390529^{* * *}$ & 0.01342 & 0.03192 & 0.80809 & 1.74386 \\
DEPO & -0.003332 & -0.0005 & -0.0041 & $0.0011^{* * *}$ & $-0.0067^{* * *}$ \\
AGER & -0.049476 & -0.0072 & -0.0506 & -0.0596 & -0.0846 \\
TRADE & $0.095209^{* * *}$ & 0.02745 & 0.07987 & 0.08831 & 0.11329 \\
GDPGR & -0.064215 & -0.0704 & -0.1542 & -0.0204 & 0.0249 \\
POP & $0.986265^{* * *}$ & 1.28753 & 1.03715 & 0.50178 & 2.24181 \\
Cons & $5.595294^{* * *}$ & 4.29851 & 7.2871 & 8.92636 & 5.11528 \\
\hline
\end{tabular}

Notes: The dependent variable is the Z-score which compares a bank's buffers capitalization and returns with the volatility of those returns. ${ }^{*} \mathrm{p}<0.05,{ }^{* *} \mathrm{p}<0.01,{ }^{* * *} \mathrm{p}<0.001$

In a similar vein, Figure 1 shows the QR coefficients plotted with confidence intervals on the same figure. The figure also shows the estimates of the OLS estimates alongside the QR estimation. The two dotted red parallel lines represent the OLS confidence intervals. Indeed, if the QR coefficient estimates falls within the OLS coefficients, then there is no significant difference between them, else, the opposite is true. Based on the figure, it could be seen that the QR estimates alongside OLS estimates shows that all the variables (except AGER and TRADE) are plotted outside of the confidence level. In addition, at the initial quantiles, BANKBR variable is associated with insignificant coefficient from 0.6 to 0.2. It became positive and significant at higher quantiles. The findings show that financial inclusion can solve the problem of income inequality and financial stability in OIC countries.

Figure 1.

\section{QR vs. OLS Regression Estimates}

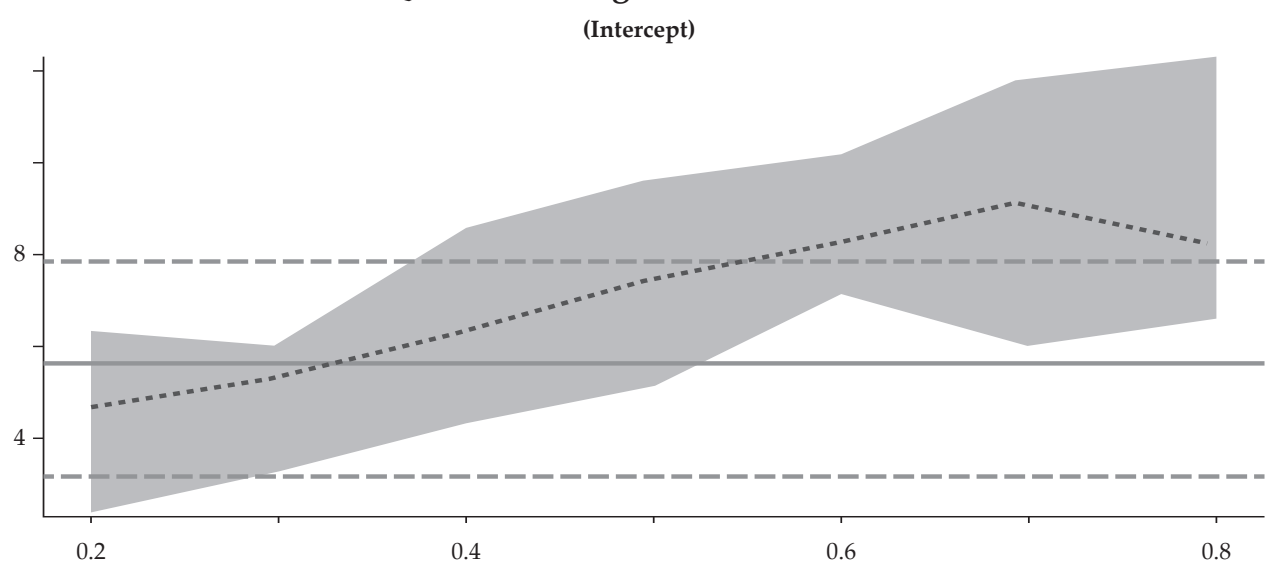


Figure 1.

\section{QR vs. OLS Regression Estimates (Continued)}
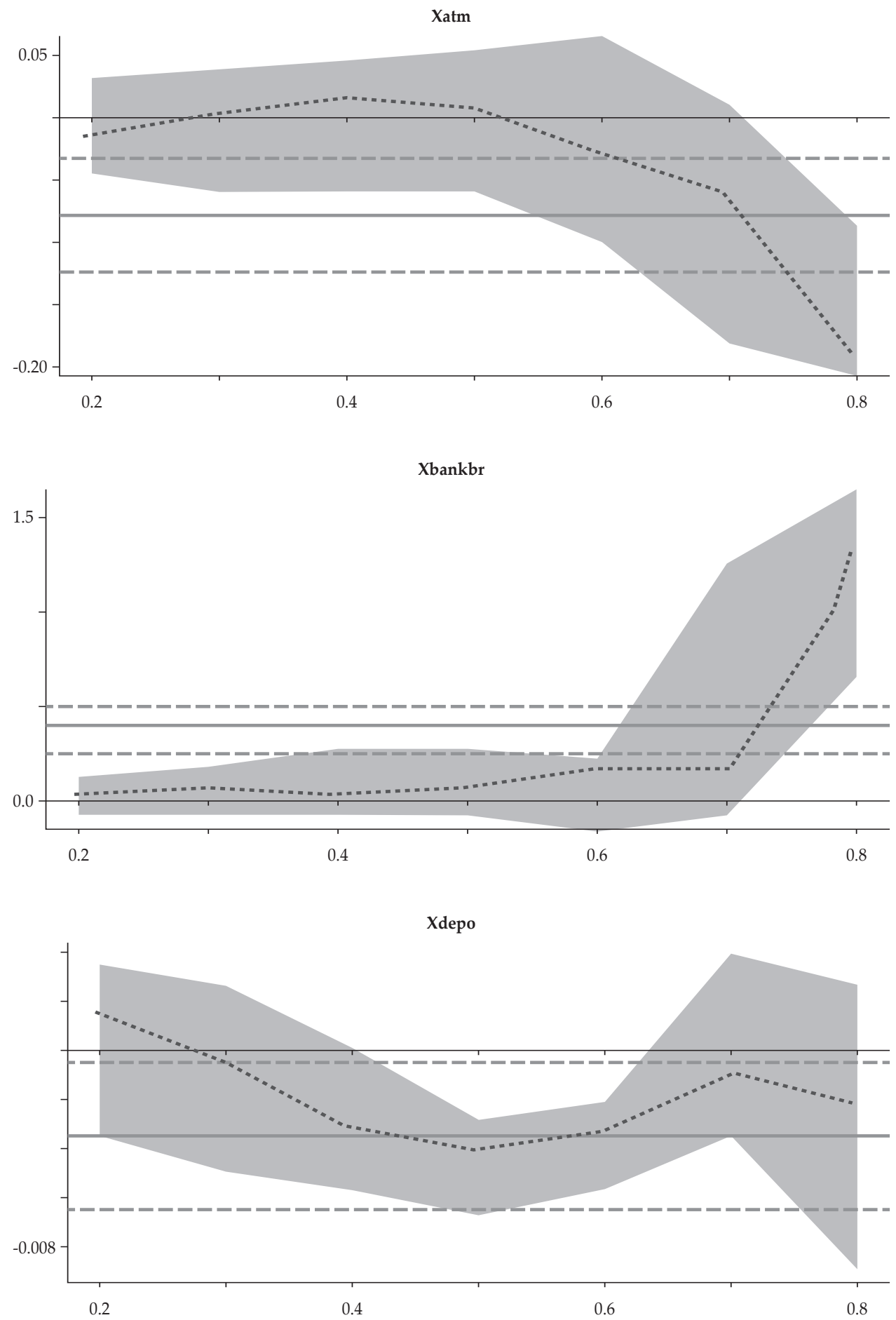
Figure 1.

\section{QR vs. OLS Regression Estimates (Continued)}
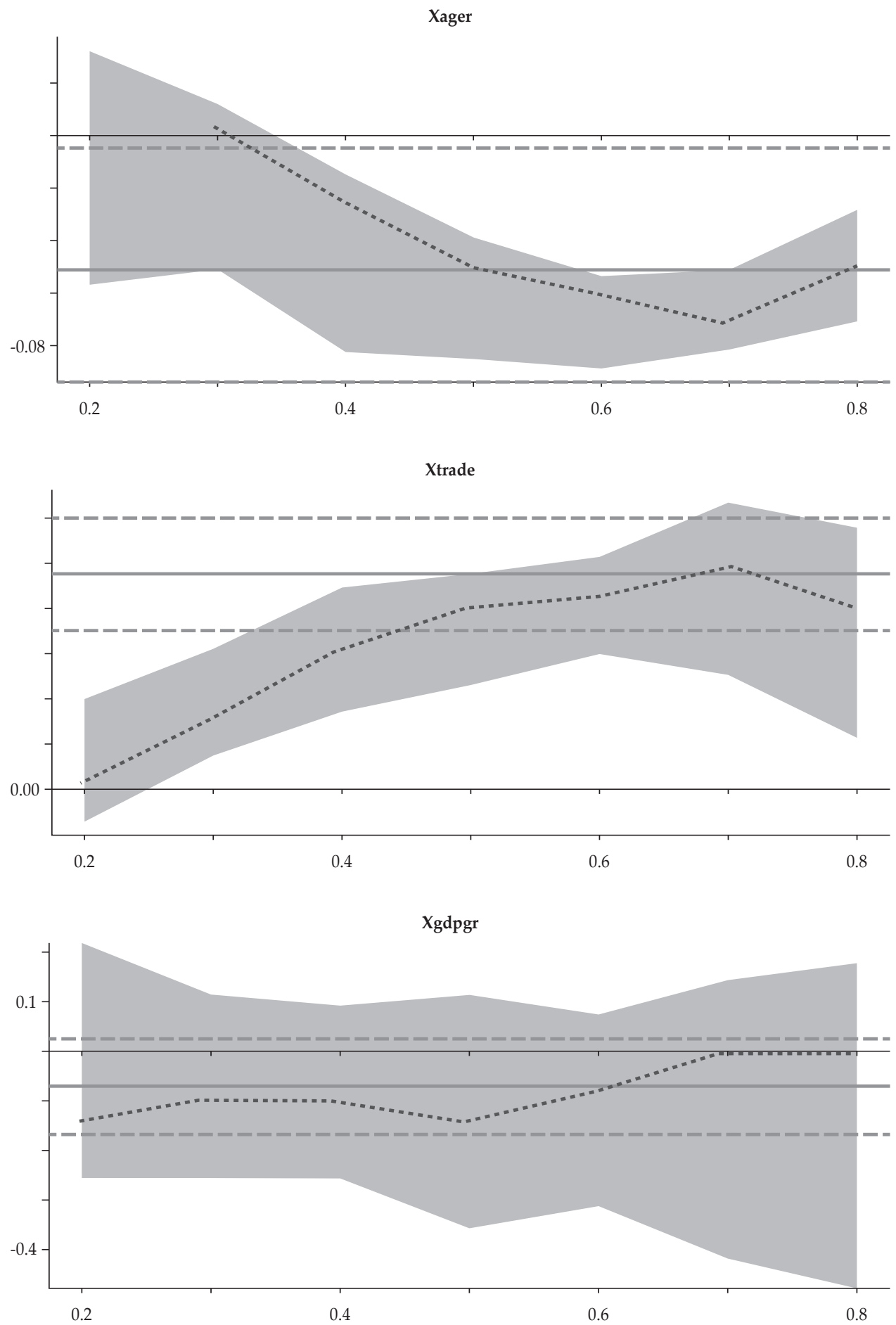
Figure 1.

\section{QR vs. OLS Regression Estimates (Continued)}

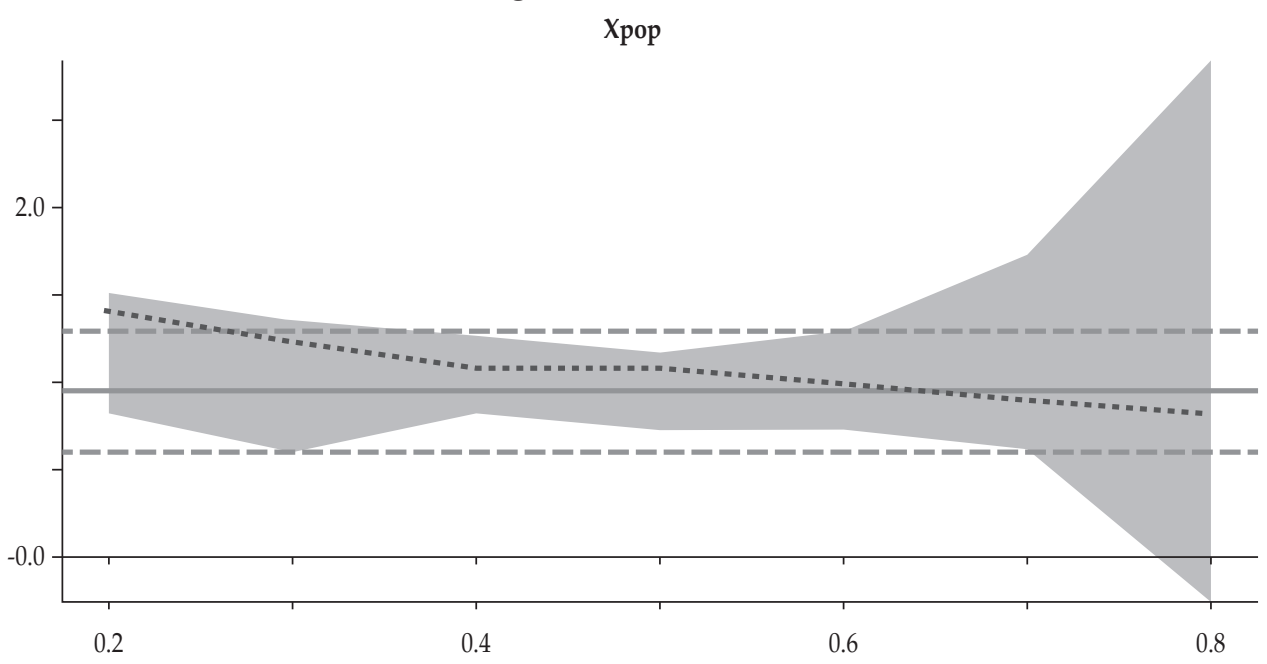

\section{CONCLUSION AND RECOMMENDATION}

This paper analyzed the effects of financial inclusion on financial stability and income inequality in OIC countries. The study employs both static and dynamic panel data estimates. For the static model, Ordinary Least Square Regression (OLS), Fixed Effects (FE) and Random Effect (RE) models were employed while for the dynamic panel model, System GMM estimation was used. As a robust test, quantile regression (QR) estimation was used from 2006 - 2016. The empirical findings show that financial inclusion contributed in narrowing the gap between the rich and poor in OIC countries. Concerning financial stability, the result support finance ability in providing stability in the selected countries under study. On the macroeconomic variables that were used as controlled variables, it is found that population growth plays a significant role in destabilizing the financial systems of OIC countries.

As more and more Muslims countries liberalized their financial system in order to provide greater finance access and reach, more opportunities for growth will be available thereby buttressing the existing financial structure. Muslims countries are still at early stage of economic development and this is why finance is contributing to the economic development of the countries. Policies aimed at making financial sector contribute to the development of the real sector and by extension affect the distribution of income should be giving priority so that more economic development can be achieved. This will in effect have positive impact on the entire society. By so doing, greater economic prosperity will be realized capable of creating robust and stable economy in OIC countries.

The results of the study have important policy implications. First, government officials in OIC countries should continue to encourage its citizens on the importance of having formal bank accounts as it is shown in this study to have helped account holders to engage in productive economic activities which helps in narrowing the gap between the haves and have not's. This can be done through 
granting more operational licenses to commercial bank operators (both domestic and international) to set up more bank branches so that financial services become more prevalent and available for the masses. In addition, as most developing countries systems are characterized by bureaucratic red tapes where it is difficult obtaining license of any sort, financial service providers intending to operate in the countries should be given waivers and incentives which will entice them to open more branches in the countries.

Second, it is evident that financial inclusion has positive and significant effect on economic development. Researchers could further take the topic to the next level by looking at different indicators of financial inclusion using primary data. This will further support the existing study that is mostly skewed to secondary data. In addition, employing different research technique might provide new insights as to the relevance of finance in daily affairs of the people. Furthermore, researchers can take longer period data set and test the short run and long run effect of financial inclusion on stability and income inequality.

\section{REFERENCES}

Ahamed, M. M. and Mallick, S. K. (2017a) 'Is Financial Inclusion Good for Bank Stability? International Evidence., Journal of Economic Behavior and Organization. Elsevier B.V., 157, pp. 403-427. doi: 10.1016/j.jebo.2017.07.027.

Ahamed, M. M. and Mallick, S. K. (2017b) 'Is Financial Inclusion Good for Bank Stability? International Evidence., Journal of Economic Behavior and Organization. Elsevier B.V. doi: 10.1016/j.jebo.2017.07.027.

Al-Smadi, O., M. (2018) 'The Role of Financial Inclusion in Financial Stability: Lesson from Jordan', Banks and Bank Systems, 13(4), pp. 31-39. doi: 10.21511/ bbs.13(4).2018.03.

Allen, F. E. et al. (2013) 'Resolving the African Financial Development Gap: CrossCountry Comparisons and a within - Country Study of Kenya.', World Bank Policy working Paper No. 6592. Washington, DC.

Beck, T., Demirgüç-Kunt, A. and Levine, R. (2007) 'Finance, Inequality and The Poor', Journal of Economic Growth, 12(1), pp. 27-49. doi: 10.1007/s10887-0079010-6.

Blundell, R. and Bond, S. (1998) 'Initial Conditions and Moment Restrictions in Dynamic Panel Data Models, Journal of Econometrics, 87(1), pp. 115-143. doi: 10.1016/S0304-4076(98)00009-8.

Bond, S. R., Hoeffler, A., and Temple, J. (2009) 'GMM Estimation of Empirical Growth Models, CEPR Discussion Papers, no. 3048 (URL). http://www.cepr.org/ pubs/dps/DP3048.asp.

Bruhn, M. and Love, I. (2014) 'The Real Impact of Improved Access to Finance: Evidence from Mexico.', The Journal of Finance 69, 1347-1376.

Brune, L. et al. (2011) 'Commitments to Save: A Field Experiment in Rural Malawi.', World Bank Policy Research Working Paper No. 5748. Washington, DC.

Burgess, R. and Pande, R. (2005) 'Do Rural Banks Matter? Evidence from the Indian Social Banking Experiment', Am. Econ. Rev. 95, 780-795. 
Clarke, G. R. G., Xu, L. C. and Zou, H. (2006) 'Finance and Income Inequality : What Do the Data Tell Us ?', Southern Economic Journal, 72(3), pp. 578-596. doi: $10.2307 / 20111834$.

Dabla-Norris, E. et al. (2015) 'Causes and Consequences of Income Inequality: A Global Perspective', (IMF Staff.

Dienillah, A. A., Anggraeni, L. and Sahara (2018) 'Impact of Financial Inclusion on Financial Stability Based on Income Group Countries', Bulletin of Monetary Economics and Banking, Bank Indonesia, vol. 20(4), pages 1-14, April.

Galor, O. and Moav, O. (2004) 'From Physical to Human Capital Accummulation: Inequality and the Process of Development', Review of Economic Studies, 71(4), pp. 1001-1026. doi: 10.1111/j.1467-937X.2004.00312.x.

Honahan, P. (2007) 'Cross-Country Variation in Household Access to Financial Services.', World Bank Paper Conference on "Access to Finance," Washington, DC.

Kim, D. W., Yu, J. S. and Hassan, M. K. (2018) 'Financial Inclusion and Economic Growth in OIC Countries', Research in International Business and Finance. Elsevier, 43(December 2015), pp. 1-14. doi: 10.1016/j.ribaf.2017.07.178.

Kim, J. H. (2016) 'A Study on the Effect of Financial Inclusion on the Relationship between Income Inequality and Economic Growth', Emerging Markets Finance and Trade, 52(2), pp. 498-512. doi: 10.1080/1540496X.2016.1110467.

Koenker, R., D’Orey, V. (1987) Computing Regression Quantiles, Appl. Stat. 36, 383-393.

Koenker, R. and Bassett Jr, G. (1978) 'Regression Quantiles.', Econometrica: Journal of the Econometric Society, 33-50.

Morgan, P. J. (2014) 'Asian Development Bank Institute', (488).

Neaime, S. and Gaysset, I. (2018) 'Financial Inclusion and Stability in MENA: Evidence from Poverty and Inequality, Finance Research Letters. Elsevier, 24(September 2017), pp. 199-220. doi: 10.1016/j.frl.2017.09.007.

Park, C.-Y. and Mercado, R. (2015) 'Financial Inclusion, Poverty, and Income Inequality in Developing Asia', Ssrn, (426). doi: 10.2139/ssrn.2558936.

Park, C.-Y. and Mercado, R. (2015) 'Financial Inclusion, Poverty and Income Inequality in Developing Asia.', ADB Economics Working Paper Series, No. 426.

Perera, L. D. H. and Lee, G. H. Y. (2013) 'Have Economic Growth and Institutional Quality Contributed to Poverty and Inequality Reduction in Asia?', Journal of Asian Economics, 27, pp. 71-86. doi: 10.1016/j.asieco.2013.06.002.

Rashid, A., Yousaf, S. and Khaleequzzaman, M. (2017) 'Does Islamic Banking Really Strengthen Financial Stability? Empirical Evidence from Pakistan', International Journal of Islamic and Middle Eastern Finance and Management, 10(2), pp. 130-148. doi: 10.1108/IMEFM-11-2015-0137.

Sama, M. (2008) 'Index of Financial Inclusion', Indian Council For Research On International Economic Relations, Working pa(215), pp. 467-478. doi: 10.1007/97881-322-1650-6_28.

Stiglitz, J. E. (2012) The Price of Inequality., London: Penguin Books. Penguin Books.

Tita A. F. and Aziakpono M. J. (2017) 'The Effect of Financial Inclusion on Welfare in Sub-Saharan Africa: Evidence from Disaggregated Data.', (ERSA Working Paper, No. 679.). 


\begin{tabular}{lccc}
\hline \multicolumn{4}{c}{ APPENDIX } \\
\\
\multicolumn{1}{c}{ Table Appendix 1. } \\
Kao Co-Integration Test & & \\
& Series Name & t-statistics & Prob \\
\hline ADF & -2.3724 & 0.0088 \\
Residual variance & 7.4445 & \\
HAC variance & 10.7023 & \\
\hline Notes: The series name includes: ATM BANKBR AGER DEPO GDPGR POP TRADE ZSCORE FROM 2006 TO 2016.
\end{tabular}

Notes: The series name includes: ATM BANKBR AGER DEPO GDPGR POP TRADE ZSCORE FROM 2006 TO 2016. 